\title{
Experimental Studies on Drying-Wetting Cycle Characteristics of Expansive Soils Improved by Industrial Wastes
}

\author{
Hao Ye, Chengfu Chu (iD, Long Xu, Kunlong Guo, and Dong Li \\ School of Resources and Environmental Engineering, Hefei University of Technology, Hefei 230009, China \\ Correspondence should be addressed to Chengfu Chu; chuchengfu@163.com
}

Received 5 June 2018; Revised 26 July 2018; Accepted 16 August 2018; Published 24 September 2018

Academic Editor: Dingwen Zhang

Copyright (C) 2018 Hao Ye et al. This is an open access article distributed under the Creative Commons Attribution License, which permits unrestricted use, distribution, and reproduction in any medium, provided the original work is properly cited.

\begin{abstract}
The improved engineering properties of the expansive soil by mixing with various additives will be changed during the long-term variation of the meteorological and hydrological conditions. In the present work, a series of tests are performed to investigate the evolution of the unconfined compression strength and the Atterberg limits under drying-wetting cycling conditions for specimens treated by iron tailing sands and calcium carbide slag. Typical results of the unconfined compressive strength can be divided into three stages. The unconfined compressive strength increases initially and then decreases to reach a stable state with continuous drying-wetting process. The calcium carbide slag content $\left(\alpha_{\mathrm{CCS}}\right)$ of $10 \%$ can be determined for the minimum effect of the dryingwetting cycle on the strength of the treated specimen. An exponential relationship is established to describe the evolution of the unconfined compressive strength with the drying-wetting cycle. The liquid limit and plastic index of the specimen increase initially followed by a decreasing trend, while a reverse trend was observed for that of the plastic limit during the drying-wetting process. The minimum effect of the drying-wetting cycle on the Atterberg limits can be presented for the specimen with $\alpha_{\mathrm{CCS}}$ of $10 \%$ as well.
\end{abstract}

\section{Introduction}

Expansive soil is widely distributed in more than 40 countries around the world. Due to the highly contained hydrophilic clay minerals, such as montmorillonite and illite, significant swelling or shrinkage characteristics appear when the expansive soil gains or loses water, respectively. As a result, railway, highway, and buildings in the area of expansive soil severely suffer from ground deformation hazards, which are needed to be avoided in engineering practices $[1,2]$. Based on the previous researches, industrial wastes were widely adopted to mix with the expansive soil for the improvement of the roadbed filler consisting of the expansive soil. Common conclusions had been reached that the volumetric deformation of the expansive soil could be effectively controlled by incorporation of the industrial wastes. However, in further period of operation, the meteorological and hydrological changes in the area of expansive soil induce drying-wetting cycling effects, which could result in secondary deterioration of the roadbed fillers consisting of the treated expansive soils, i.e., significant swelling/shrinkage behavior and limited bearing capacity $[3,4]$. Therefore, profound understanding of the engineering properties of the treated expansive soils under dryingwetting cycling conditions is of great significance to the engineering application.

In the previous researches, Gens and Alonso [5] and Alonso et al. [6] investigated the deformation properties of the expansive soil after drying-wetting cycles. Test results presented significant volumetric deformations of the specimens during the cycles. However, the magnitude of the deformation decreases with the increase in the dryingwetting cycle, failing to restore the initial state, which confirmed an irreversible influence of the drying-wetting cycle on the deformation properties of the soils. In further cyclic swell-shrink tests performed on reconstituted specimens, less expansion and shrinkage magnitude, decreased strength, and significant fatigue behavior of the specimen could also be observed during the drying and wetting cycling process, which were attributed to the rearrangement of the 
soil particles and destruction of the microstructure [7-9]. Researches performed by Dong and wang [10], Kay and Dexter [11], and Yang and Xiao [12] reported that, with the continuous drying and wetting, the strength and compressibility of the specimen, respectively, decrease and increase in the initial cycles followed by stable trends in the later period. In further step, logarithmic and powder models were successfully adopted to describe the evolutions of strength and compressibility of the specimens with the number of cycles. The effects of the drying-wetting cycles on the shear strength of the specimens were also investigated by Malusis et al. [13], Zhang et al. [14], and Shi et al. [15]. Results showed that, in the early stage of drying-wetting, the number of macrocracks and microcracks in the specimen decreased and increased, respectively. As a result, the structure of the treated expansive soil would be destroyed due to the water infiltration, which would reduce the strength and increase the compressibility of the specimen. Explanations proposed by Wang and Wei [16] indicated that the effect of drying-wetting cycle on the engineering property of clay was attributed to the irreversible volume shrinkage, the increase of large pore volume, and the development of microfissure. The effects of the drying-wetting cycle on the Atterberg limits of specimens were tested and analyzed by Rao et al. [17] and Yang et al. [18]. Results reported that the liquid limit and plasticity index of the specimen increased in the initial period of the dryingwetting cycles followed by a stable state in the latter period. Explanation proposed by Mitchell [19] indicated that the Atterberg limits were related to the water adsorbed in the double electron layer on the surface of the soil particles, which was mainly affected by the size and specific surface area of the particles. The fine particle content in the specimen will increase with the continuous drying-wetting process, which contributed to the increase of liquid limit and plasticity index of the treated specimen.

As presented in previous researches, the engineering properties of the treated expansive soils under dryingwetting cycling conditions were mainly acquired on the basis of qualitative investigations. In the present work, the industrial wastes including iron tailing sands and calcium carbide slag are adopted to treat the expansive soils. After this, the evolution of the engineering properties of the treated soils under drying-wetting cycling conditions is experimentally and quantitatively investigated.

\section{Materials and Testing Procedures}

2.1. Materials. The soils adopted in the present work were sampled from a foundation pit in Hefei city, Anhui province, China (Figure 1). The basic physical properties of the soils are summarized in Table 1. As shown in Table 1, the free swelling ratio of the soil is in the range of $40 \% \sim 60 \%$, which could be classified as the weak expansive soils [20-22]. The maximum dry density of $1.83 \mathrm{~g} / \mathrm{cm}^{3}$ and the optimum water content of $16.5 \%$ are also determined by performing the compaction test as shown in Figure 2. The particle-size distribution of the tested soil is obtained by using the laser particle size analyzer (Figure 3), which shows the nonuniform coefficient of 3.16 and curvature coefficient of 0.93 .

The industrial wastes including iron tailing sand (ITS) and calcium carbide slag (CCS) were sampled in Anhui, China, which were adopted to treat the expansive soils in the present work (Figure 1). The corresponding chemical components were determined by the X-ray fluorescence (XRF) technique as shown in Table 2. The particle-size distribution of the iron tailing sand is shown in Table 3.

2.2. Testing Procedures. The specimens in the present work were prepared by mixing the expansive soils with the industrial wastes including iron tailing sand and calcium carbide slag. The content of iron tailing sand was fixed at $30 \%$ by mass, while the content of calcium carbide slag changing from $6 \%$ to $14 \%$ was designed in specimen preparation. Then, denotations of $\alpha_{\mathrm{CCS}}$ (calcium carbide slag content) were created to represent the mass ratio of the calcium carbide slag to the mixtures.

During specimen preparation, the materials including the expansive soils and the industrial wastes were oven-dried at $100^{\circ} \mathrm{C}$ for $36 \mathrm{~h}$, then grounded into powders, and sized through a $0.5 \mathrm{~mm}$ sieve. According to the optimum water contents determined by compaction tests performed on previously designed mixtures (Figure 4), a certain amount of water was homogeneously mixed with the powders of expansive soil, iron tailing sands, and calcium carbide slag which was cured in a period of $24 \mathrm{~h}$. After this, a target amount of mixtures were statically compacted into a mould to obtain a target cylindrical specimen with a dimension of $50 \mathrm{~mm}$ in height, $50 \mathrm{~mm}$ in diameter, and the designed dry density equaled to $95 \%$ of the maximum dry density. Finally, the prepared specimens were maintained under standard curing conditions (temperature $20^{\circ} \mathrm{C}$ and relative humidity 95\%) for 14 and 28 days, respectively.

When the curing was finished, the specimens were taken out to perform the dying-wetting cycling tests $[23,24]$. In the drying process, each specimen was wrapped with plastic film and placed in an oven with temperature at $60 \pm 1^{\circ} \mathrm{C}$ for $23 \mathrm{~h}$. In the subsequent wetting process, the specimen was taken out from the oven and placed on a porous stone in an immersion chamber with temperature at $20 \pm 1^{\circ} \mathrm{C}$ for $1 \mathrm{~h}$ (Figure 5). After this, distilled water was continuously added to immerse the porous stone and maintained for $23 \mathrm{~h}$. Finally, the specimen was taken out of the chamber followed by $1 \mathrm{~h}$ equilibrium. Then the procedures mentioned above were repeated for $1,3,5,7,10$, and 15 cycles.

After the designed drying-wetting cycles, the unconfined compressive strength tests were performed on the specimens following the Standard Test Method for Unconfined Compressive Strength of Cohesive Soil (ASTM D2166-06) [25]. The YHS- $2^{\circledR}$ UCS testing apparatus with a vertical strain rate of $1 \% /$ min was adopted in the test, and three parallel specimens were tested in each test with the average value as the representative one. Tests for determination of the Atterberg limits were carried out according to the Standard Test Methods for Liquid Limit, Plastic Limit, and Plasticity Index of Soils (ASTM D4318-17) [26]. Two parallel specimens were 


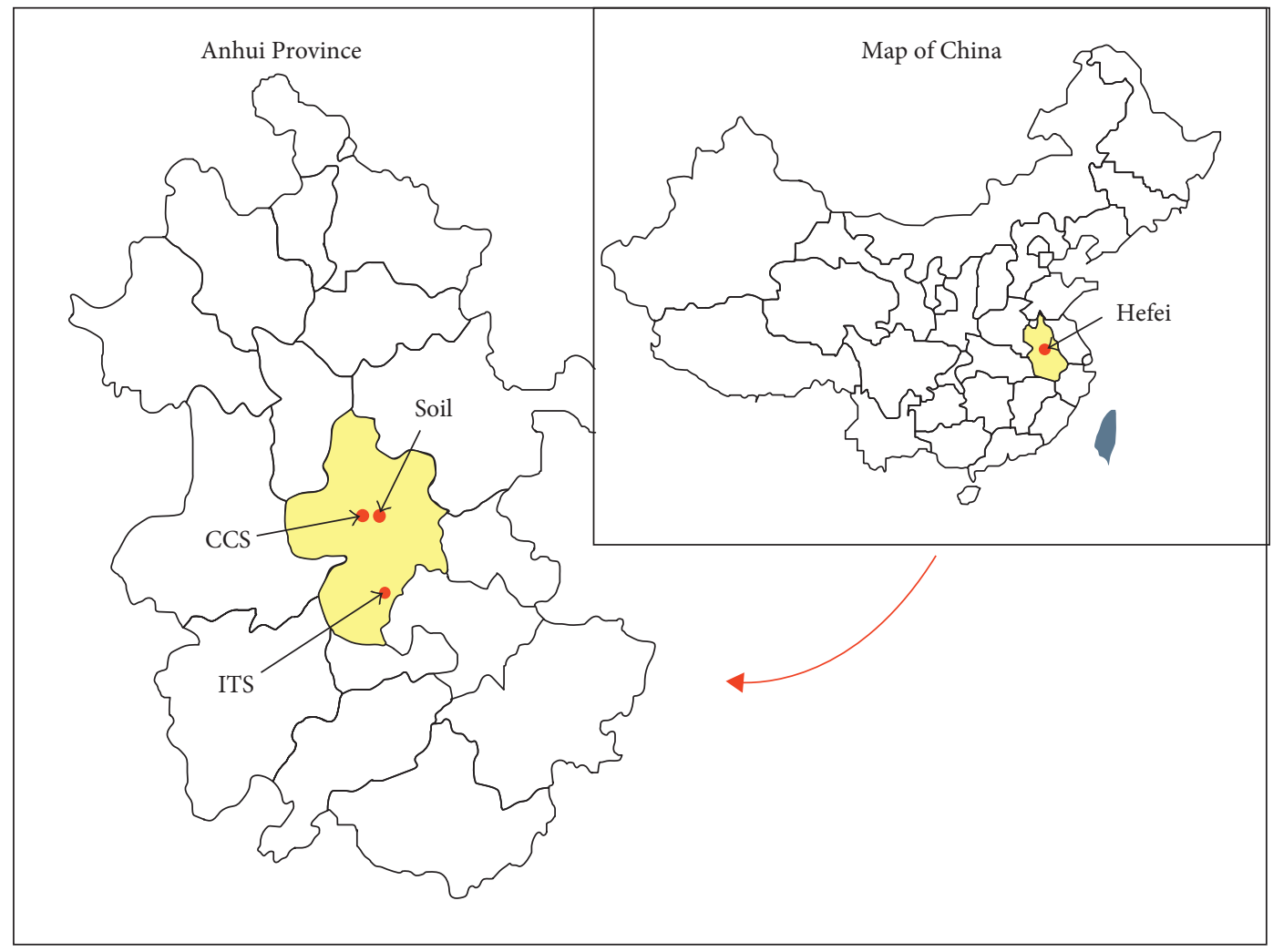

Figure 1: Sampling sites of the tested materials.

TABLe 1: Basic physical properties of the tested soils.

\begin{tabular}{lcccccc}
\hline Density $(\mathrm{g} / \mathrm{cm})$ & Specific gravity & Void ratio & Liquid limit $(\%)$ & Plastic limit $(\%)$ & Plasticity index & Free swelling ratio (\%) \\
\hline 1.92 & 2.72 & 0.76 & 46.6 & 22.1 & 24.5 & 53 \\
\hline
\end{tabular}

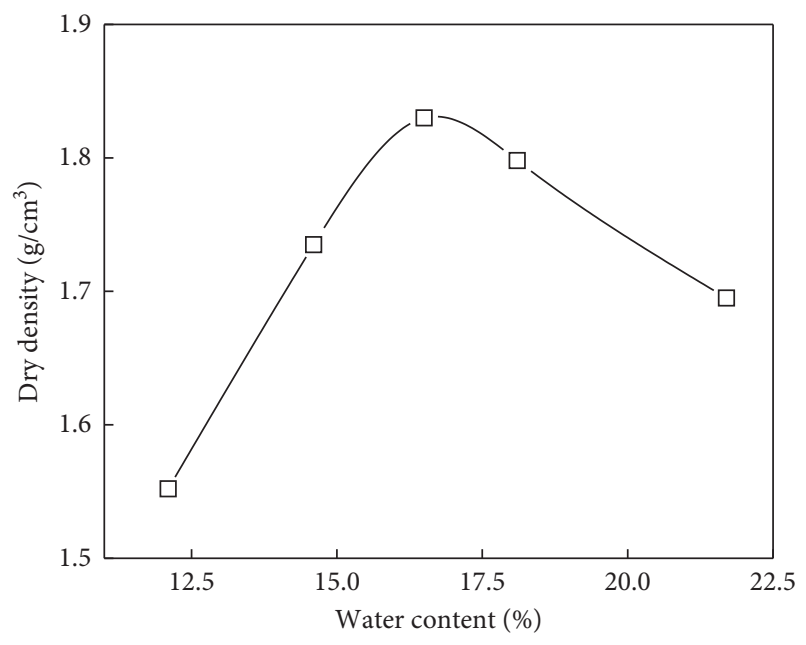

Figure 2: Compaction curve of the tested soils.

tested in each test with the average value as the representative one. In addition, the fine particle content $(<0.002 \mathrm{~mm})$ of the specimen after drying-wetting cycles was determined by performing particle-size analysis for mechanism research.

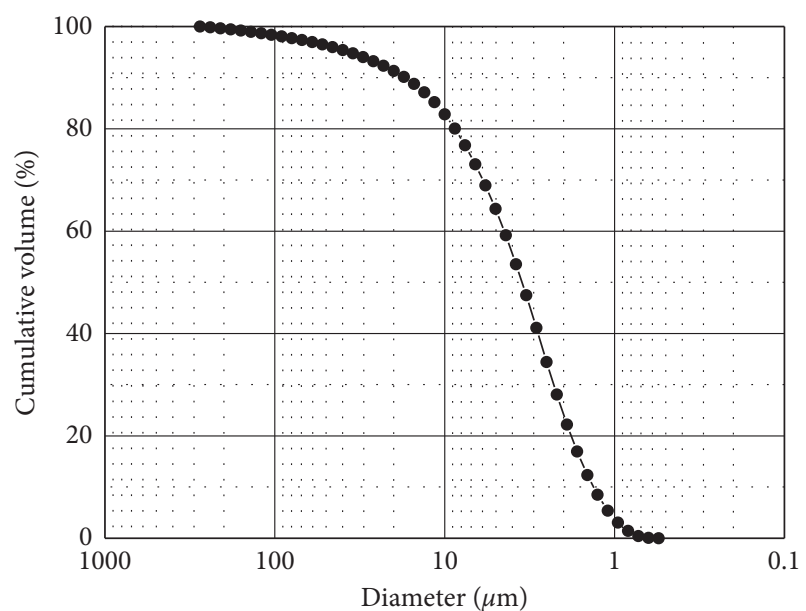

FIgURe 3: Particle-size distribution of the tested soil.

\section{Test Results and Analysis}

3.1. Unconfined Compressive Strength. Evolutions of the unconfined compressive strength with the number of drying-wetting cycles for specimens tested in the present work are shown in Figure 6. 
TABLE 2: Chemical component of iron tailing sands and calcium carbide slag.

\begin{tabular}{lccccccc}
\hline Components & & $\mathrm{SiO}_{2}$ & $\mathrm{Al}_{2} \mathrm{O}_{3}$ & $\mathrm{Al}_{2} \mathrm{O}_{3}$ & $\mathrm{CaO}$ & $\mathrm{MgO}$ & $\mathrm{SO}_{3}$ \\
\hline \multirow{2}{*}{ Contents (\%) } & ITS & 65.51 & 9.31 & 11.73 & 3.18 & 5.75 & 0.71 \\
& $\mathrm{CCS}$ & 6.21 & 3.79 & 0.51 & 63.43 & 0.27 & 0.19 \\
\hline
\end{tabular}

TABle 3: Particle-size distribution of the iron tailing sands.

\begin{tabular}{lcccc}
\hline$<2 \mathrm{~mm}$ & $<1 \mathrm{~mm}$ & $<0.5 \mathrm{~mm}$ & $<0.25 \mathrm{~mm}$ & $<0.075 \mathrm{~mm}$ \\
\hline 97.25 & 91.45 & 72.27 & 51.97 & 6.98 \\
\hline
\end{tabular}

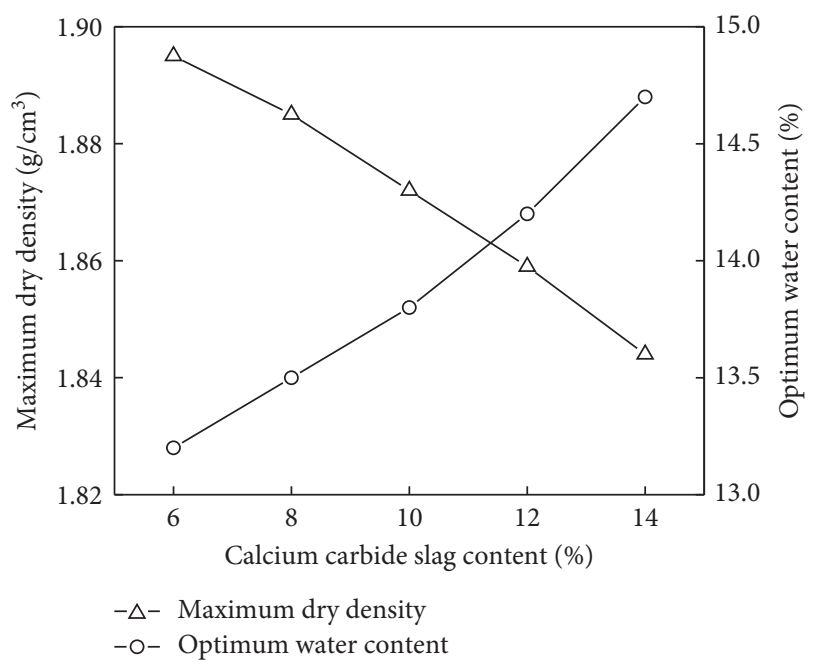

FIGURE 4: Compaction curves of the mixtures with different calcium carbide slag contents.

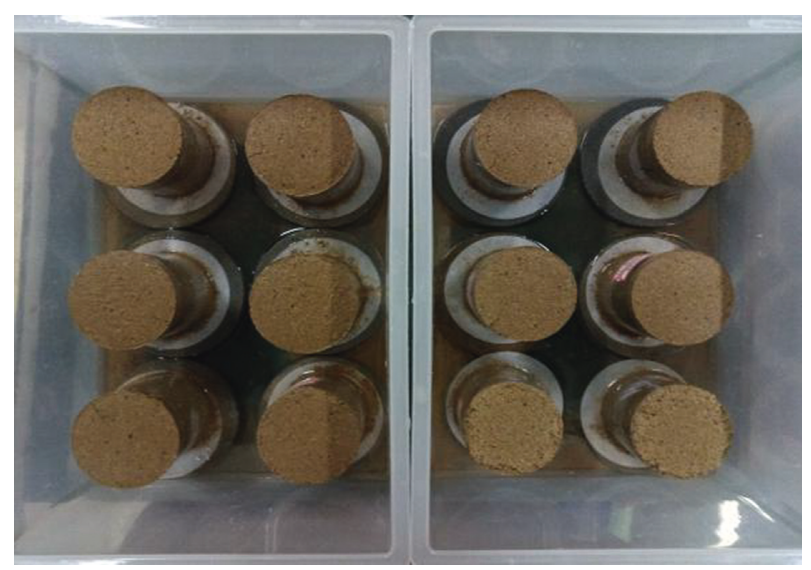

FIGURE 5: Drying-wetting cycling test in the present work.

As shown in Figure 6(a), for the specimens with a curing time of $14 \mathrm{~d}$, the evolution of the unconfined compressive strength with the drying-wetting cycles can be divided into three stages. Initially, the unconfined compressive strength increases with the increase of the drying-wetting cycle, which could be attributed to the uncompleted physical and chemical reactions between the calcium carbide slag, the expansive soil, and the existing water in the specimen. After the achievement of the peak value, the unconfined compressive strength starts to decrease and the decreasing rate reduces with the increase of the drying-wetting cycle. In this stage, the repeated drying-wetting process will induce the microcracks and destroy the integrity of the specimen followed by the infiltration of the water along the cracks, which results in the reduction of the unconfined compressive strength. Finally, after 10 cycles of dryingwetting, the unconfined compressive strength tends to be stable due to the limited variation of the microstructure of the specimen. As shown in Figure 6(b), a slight difference could be observed for the specimen with a curing time of $28 \mathrm{~d}$, and only the latter two stages are presented in the strength evolution with the drying-wetting process, which is due to the completed physical and chemical reactions between the industrial wastes and the soils during the $28 \mathrm{~d}$ curing time.

The curves in Figure 6 also show significant effect of calcium carbide slag content $\left(\alpha_{\mathrm{CCS}}\right)$ on the strength. In further analysis, the stable values of the unconfined compressive strengths after 15 drying-wetting cycles are extracted (Figure 7). As shown in Figure 7, the unconfined compressive strength increases initially and then decreases with $\alpha_{\mathrm{CCS}}$ increasing. The maximum value of the strength is reached when $\alpha_{\mathrm{CCS}}$ equals to $10 \%$. It is clear that the initial increase of the calcium carbide slag content in the specimen will result in more intensive crystallization, pozzolanic, and carbonation reactions between the calcium carbide slag and the soils. Then the strength of the specimen increases with the formation of the hydrated calcium silicate, hydrated calcium aluminate, and $\mathrm{CaCO}_{3}$ crystal. However, when a critical value of $\alpha_{C C S}$ is reached, the strength of the specimen will be controlled by the calcium carbide slag, which results in decreased strength of the specimen due to the lower strength of calcium carbide slag than that of the soil. According to the results presented in Figure 7, the critical $\alpha_{\mathrm{CCS}}$ could be determined as $10 \%$, which is the optimal value for improvement of the expansive soils by mixing with the industrial wastes.

In further step, since the uncompleted physical and chemical reactions between the calcium carbide slag, the expansive soil, and the existing water in the specimen, an exponential relationship is established to describe the evolution of the unconfined compressive strength with the drying-wetting cycles for the specimen with a curing time of $28 \mathrm{~d}$, which is shown in Figure 8 and Equation (1), and the specific parameters for all tests are listed in Table 4:

$$
q_{\mathrm{u}}=A \cdot \exp (B \cdot N)+C,
$$

where $q_{\mathrm{u}}$ is the unconfined compressive strength, $\mathrm{MPa}$, and $N$ is the number of drying-wetting cycles.

It is clearly shown in Table 4 that the parameters $A$ and $B$ are almost independent of the variation of $\alpha_{\mathrm{CCS}}$. Then, the average values of 2.0 and -0.20 can be adopted as the representative ones for $A$ and $B$, respectively. The parameter $C$ is strongly dependent on the variation of $\alpha_{\mathrm{CCS}}$. According to the researches performed by Dong and Wang [10], a linear 


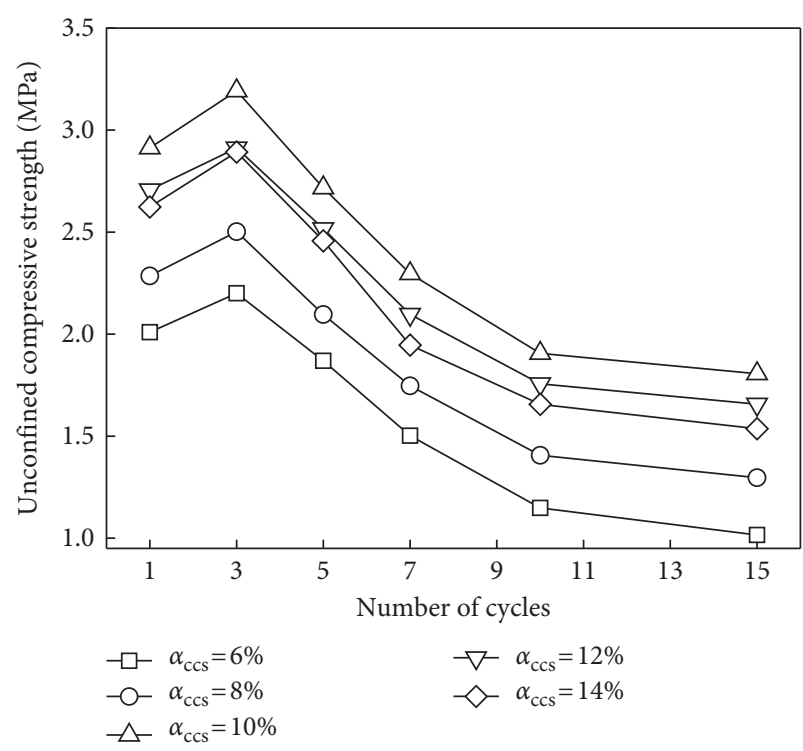

(a)

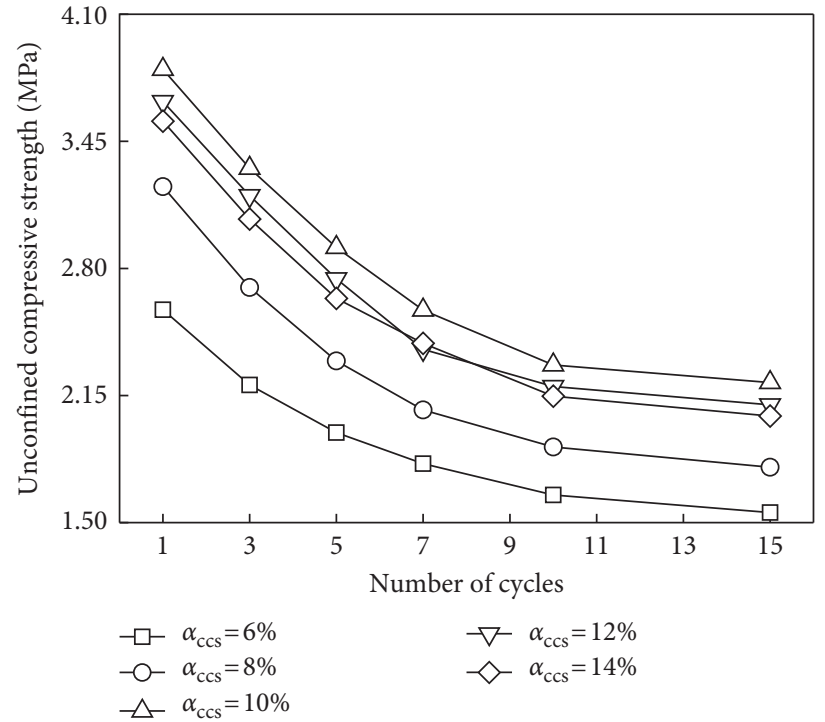

(b)

Figure 6: Evolutions of the unconfined compressive strength during the drying-wetting process. Curing time: (a) $14 \mathrm{~d}$ and (b) $28 \mathrm{~d}$.

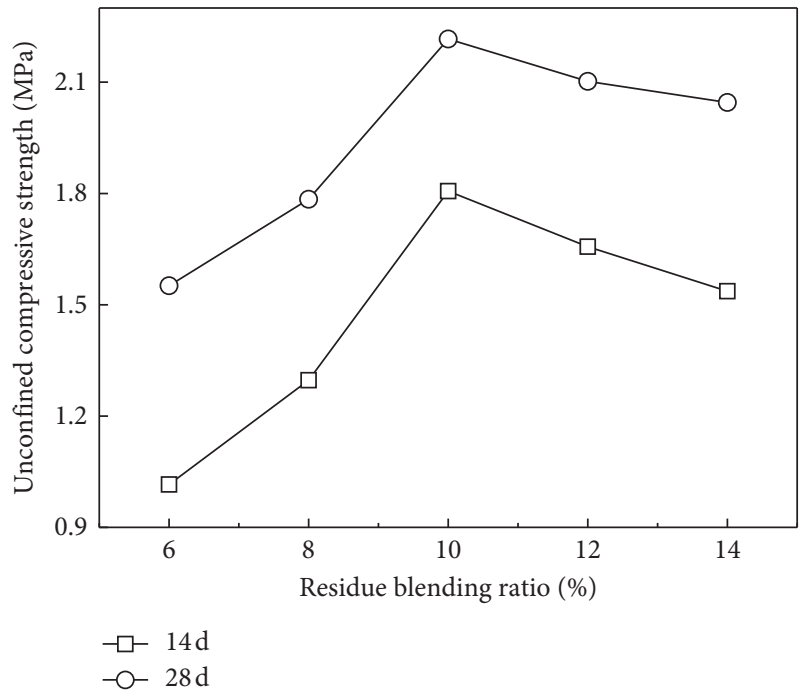

FIGURE 7: Evolutions of strength with the calcium carbide slag content.

relationship between the initial strength and the parameter $C$ is established as presented in the following equation:

$$
C=K \cdot q_{\mathrm{u} 0},
$$

where $q_{u 0}$ is the initial unconfined compressive strength of the specimen $(\mathrm{MPa})$, which equals to $2.59 \mathrm{MPa}, 3.19 \mathrm{MPa}$, 3.82 $\mathrm{MPa}, 3.65 \mathrm{MPa}$, and $3.55 \mathrm{MPa}$ for the specimen with $\alpha_{\text {CCS }}$ of $6 \%, 8 \%, 10 \%, 12 \%$, and $14 \%$, respectively, and $K$ is the linear coefficient that can be determined in the evolution of the parameter $K$ with the calcium carbide slag content (Figure 9). It is evident that the variation of $K$ is limited and average value of 0.54 can be used in the present work.

By submitting the values of parameters $A, B$, and $K$ and Equation (2) into Equation (1), the empirical relation

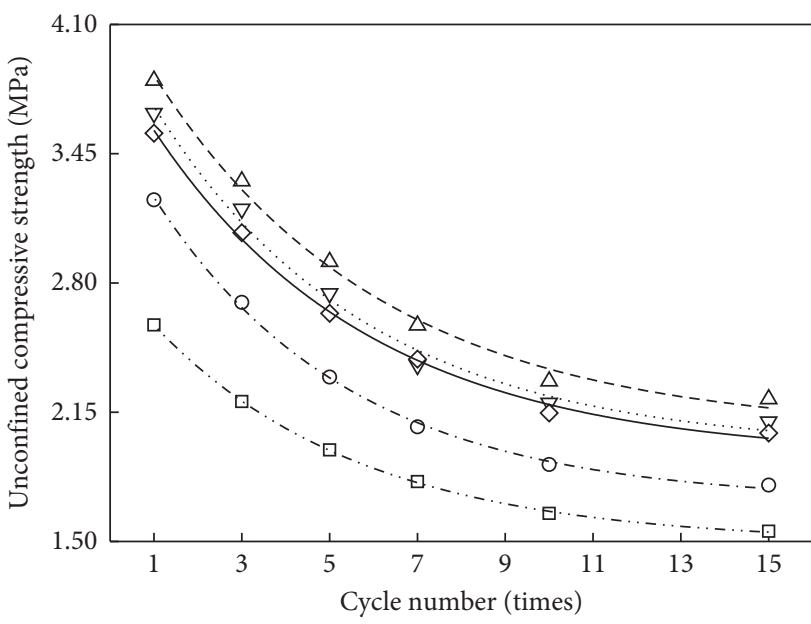

$$
\begin{aligned}
& \text { 口 Measured result: } \alpha_{\text {ccs }}=6 \% \quad-\text { Fitted result: } \alpha_{\text {ccs }}=6 \% \\
& \text { ○ Measured result: } \alpha_{\text {ccs }}=8 \% \quad \text { - - - Fitted result: } \alpha_{\text {ccs }}=8 \% \\
& \triangle \text { Measured result: } \alpha_{\mathrm{ccs}}=10 \% \text {..... Fitted result: } \alpha_{\mathrm{ccs}}=10 \% \\
& \nabla \text { Measured result: } \alpha_{\mathrm{ccs}}=12 \% \text {...- Fitted result: } \alpha_{\mathrm{ccs}}=12 \% \\
& \diamond \text { Measured result: } \alpha_{\mathrm{ccs}}=14 \% \ldots \text {. Fitted result: } \alpha_{\mathrm{ccs}}=14 \%
\end{aligned}
$$

FIGURE 8: Relationships between the unconfined compressive strength and the number of drying-wetting cycles.

between the unconfined compressive strength and the drying-wetting cycle can be finally determined in the following equation:

$$
q_{\mathrm{u}}=2 \cdot \exp (-0.20 N)+0.54 q_{\mathrm{u} 0}, \quad R^{2}=0.992 .
$$

It is clearly shown in Equation (3) that the strength of the specimen under the drying-wetting cycling condition is only related to the cycle number and initial strength of the specimen, which is also reflected as the parallel curves in Figure 6. Therefore, the empirical relationship can be used to predict the unconfined compressive strength of the 
TABle 4: Parameters of the exponential relationship.

\begin{tabular}{lcccc}
\hline Calcium carbide slag content (\%) & $A$ & $B$ & $C$ & Goodness-of-fit $\left(R^{2}\right)$ \\
\hline 6 & 1.85 & -0.21 & 1.49 & 0.991 \\
8 & 1.91 & -0.22 & 1.70 & 0.997 \\
10 & 2.17 & -0.19 & 2.01 & 0.991 \\
12 & 2.12 & -0.20 & 1.96 & 0.985 \\
14 & 2.01 & -0.20 & 1.92 & 0.996 \\
\hline
\end{tabular}

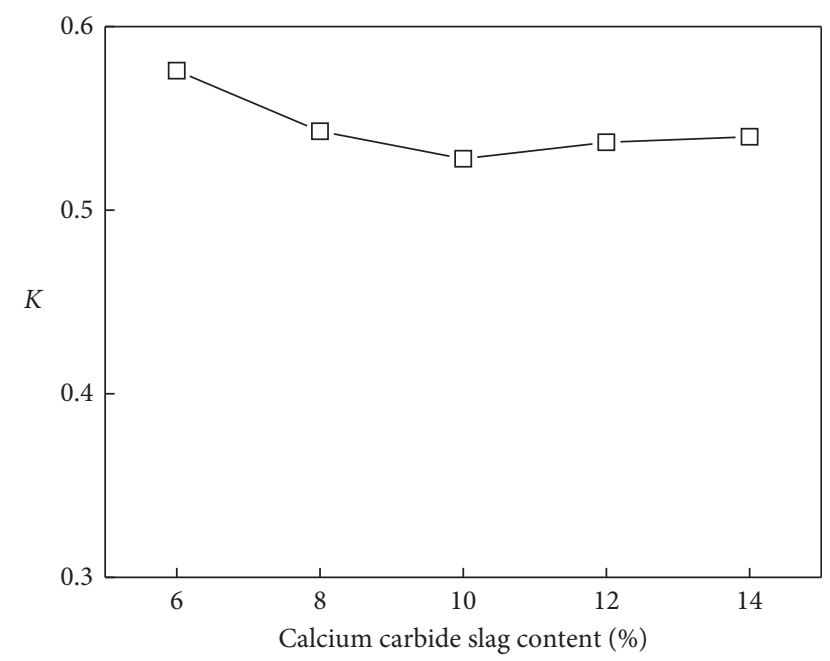

FIGURE 9: Evolutions of the parameter $K$ with the calcium carbide slag content.

expansive soils treated with iron tailing sands and calcium carbide slag under drying-wetting cycling conditions.

3.2. Atterberg Limits. The evolutions of the liquid limit and the plastic limit with the drying-wetting cycle of the treated specimen are presented in Figure 10.

As shown in Figure 10, the liquid limit of the specimen increases initially followed by a decreasing trend, while a reverse trend can be observed for the evolution of the plastic limit during the drying-wetting process. This is because that the Atterberg limits are related to the water adsorbed in the double electron layer on the surface of the soil particles, which is mainly affected by the size and specific surface area of the particles. The microstructure of the specimen will be destroyed during continuous dryingwetting cycles resulting in the increase of the fine particle content $(<0.002 \mathrm{~mm})$ in the specimen as shown in Figure 11. As a result, the liquid limit of the specimen increases and the plastic limit decreases in the initial period [19]. However, after a certain number of drying-wetting cycles, the formation of microfissures leads to the fully developed water flow in the specimen, which will wash the fine particles away and result in the decrease of the liquid limit, as well as the increase of the plastic limit, of the specimen.

In order to investigate the effect of $\alpha_{\mathrm{CCS}}$ on the Atterberg limits of the specimen, the maximum and minimum liquid limits and plastic limit of the specimen shown in Figure 10(a) are listed in Table 5. It is clear that the variations of the Atterberg limits become limited when $\alpha_{\mathrm{CCS}}$ is around $10 \%$, which implies the minimum effect of the dryingwetting cycles on the microstructure of the specimen. Therefore, it could be concluded that the optimal $\alpha_{\text {CCS }}$ for improvement of the expansive soil is around $10 \%$, which is consistent with the conclusion obtained from the unconfined compressive strength tests.

The plastic index of the specimens tested in the present work are calculated and presented in Figure 12. The curves in Figure 12 clearly showed that the plastic index of the specimen increases initially followed by a decreasing trend. This is because that the plastic index is related to the water adsorbed in the double electron layer on the surface of the soil particles, especially for the fine particles. During the continuous drying-wetting cycles, the microstructure of the specimen is destroyed and then it forms lots of fine particles in the specimen, which results in the increase of the plastic index. However, after a certain number of drying-wetting cycles, the formation of microfissures leads to the fully developed water flow in the specimen. The fine particles will be washed away along the microfissures, which results in the decrease of the plastic index.

\section{Conclusions}

In the present work, the unconfined compressive strength and the Atterberg limits of the industrial waste-treated expansive soils under the drying-wetting cycling conditions are investigated. Some main conclusions can be summarized as follows:

(1) For specimens with a curing time of $14 \mathrm{~d}$, the unconfined compressive strength initially increases with the increase of the drying-wetting cycle. After the achievement of the peak value, the unconfined compressive strength starts to decrease and the decreasing rate reduces with the increase of dryingwetting cycle. After 10 cycles of drying-wetting, the unconfined compressive strength tends to be stable. For the specimen with a curing time of $28 \mathrm{~d}$, only the latter two stages could be observed in the strength evolution with the drying-wetting process.

(2) An exponential relationship can be adopted to describe the evolution of the unconfined compressive strength with the drying-wetting cycles for expansive soils treated with iron tailing sands and calcium carbide slag.

(3) During drying-wetting cycles, the liquid limit and the plastic index of the specimen increases initially 


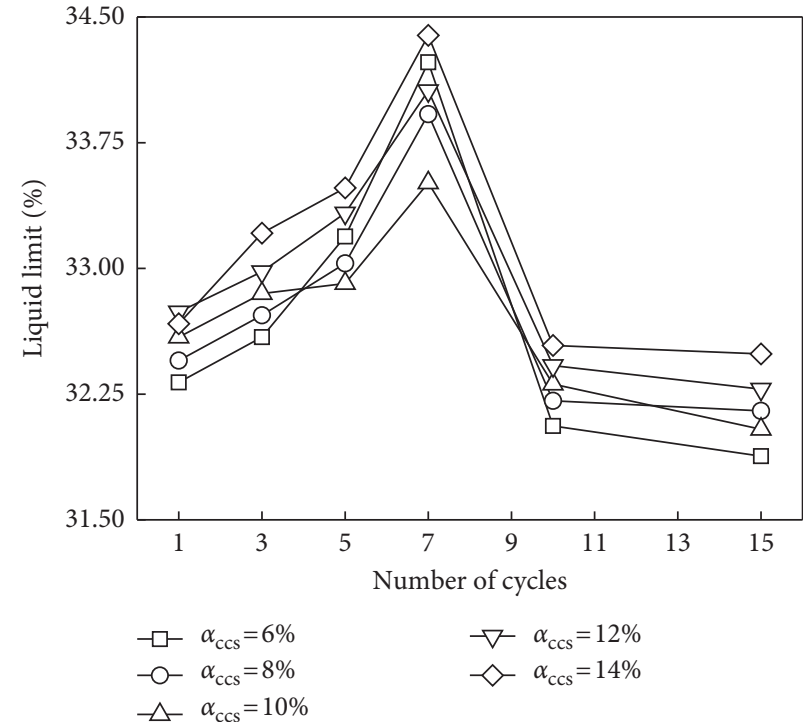

(a)

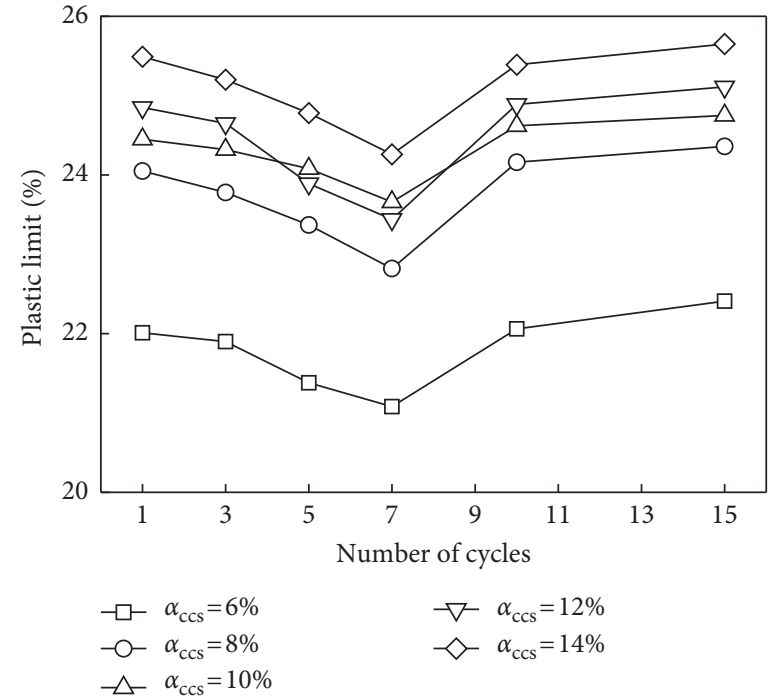

(b)

Figure 10: Evolutions of the Atterberg limits with the number of drying-wetting cycles: (a) liquid limit and (b) plastic limit.

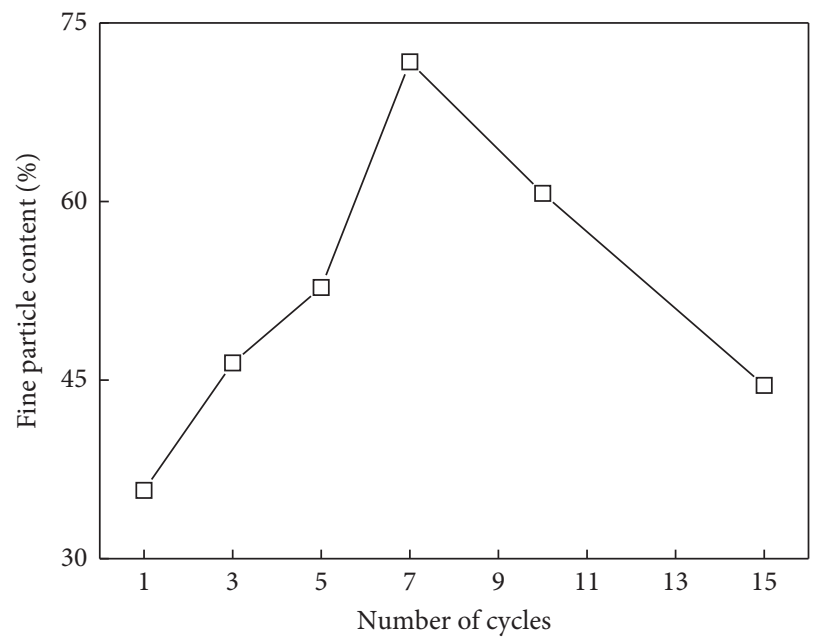

FIGURE 11: Relationships between of the fine particle content and the number of drying-wetting cycles.

TABle 5: Atterberg limits of the tested specimen.

\begin{tabular}{|c|c|c|c|c|c|c|c|c|c|c|}
\hline \multirow{2}{*}{$\begin{array}{l}\text { Calcium carbide slag } \\
\text { content }(\%)\end{array}$} & \multicolumn{4}{|c|}{ Maximum (\%) } & \multicolumn{4}{|c|}{ Minimum (\%) } & \multicolumn{2}{|c|}{$\begin{array}{c}\text { Variation } \\
\text { magnitude (\%) }\end{array}$} \\
\hline & $\begin{array}{c}\text { Liquid } \\
\text { limit }\end{array}$ & $\begin{array}{c}\text { Number of } \\
\text { cycles }\end{array}$ & $\begin{array}{c}\text { Plastic } \\
\text { limit }\end{array}$ & $\begin{array}{c}\text { Number of } \\
\text { cycles }\end{array}$ & $\begin{array}{c}\text { Liquid } \\
\text { limit }\end{array}$ & $\begin{array}{c}\text { Number of } \\
\text { cycles }\end{array}$ & $\begin{array}{c}\text { Plastic } \\
\text { limit }\end{array}$ & $\begin{array}{c}\text { Number of } \\
\text { cycles }\end{array}$ & $\begin{array}{c}\text { Liquid } \\
\text { limit }\end{array}$ & $\begin{array}{l}\text { Plastic } \\
\text { limit }\end{array}$ \\
\hline 6 & 34.23 & & 22.06 & & 31.88 & & 21.08 & & 7.37 & 4.65 \\
\hline 8 & 33.92 & & 24.36 & & 32.15 & & 22.82 & & 5.50 & 6.75 \\
\hline 10 & 33.51 & 7 & 24.75 & 10 & 32.02 & 10 & 23.66 & 7 & 4.59 & 4.60 \\
\hline 12 & 34.06 & & 25.11 & & 32.28 & & 23.44 & & 5.55 & 7.12 \\
\hline 14 & 34.39 & & 25.65 & & 32.49 & & 24.26 & & 5.58 & 5.73 \\
\hline
\end{tabular}

followed by a decreasing trend, while a reverse trend can be observed for the evolution of the plastic limit.
(4) Investigations on the unconfined compressive strength and the Atterberg limits show that the critical $\alpha_{\text {CCS }}$ of $10 \%$ could be determined as the 


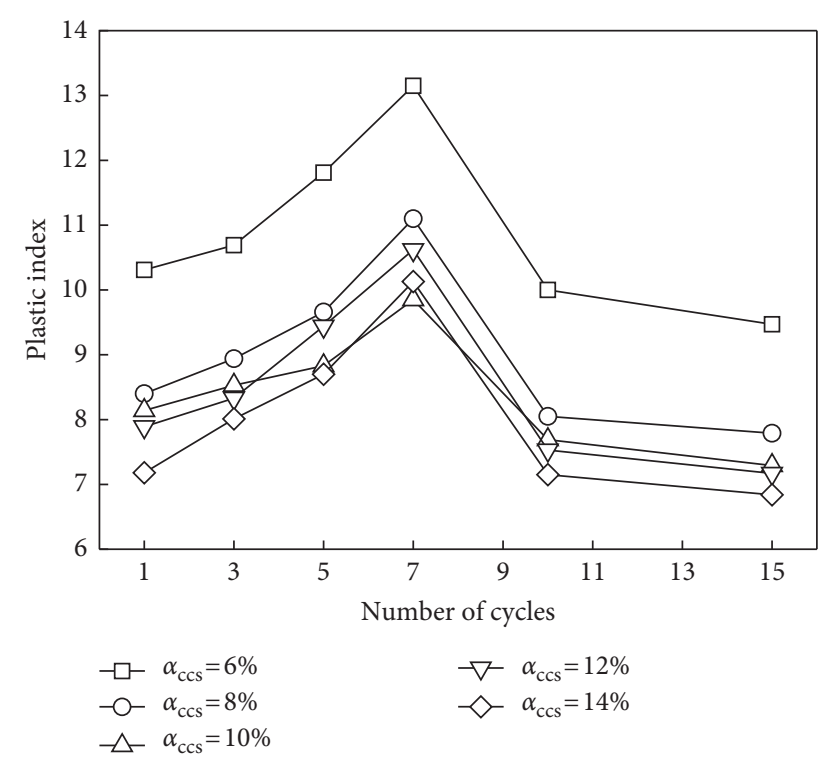

Figure 12: Evolutions of the plastic index with the number of drying-wetting cycles.

optimal value for improvement of the expansive soils by mixing with the industrial wastes, which implies the minimum effect of drying-wetting cycles on the properties of the specimen.

\section{Data Availability}

The data used to support the findings of this study are included within the article.

\section{Conflicts of Interest}

The authors declare that they have no conflicts of interest.

\section{Acknowledgments}

The authors are grateful to the financial support of Anhui Provincial National Science Foundation (Grant no. 1608085MD81), the National Science Foundation of China (Grant nos. 41572280 and 41672306), and China Scholarship Council (CSC) (Grant no. 201606695047).

\section{References}

[1] B.R. Phani Kumar, R. S. Sharma, and M. ASCE, "Effect of fly ash on engineering properties of expansive soils," Journal of Geotechnical and Geoenvironmental Engineering, vol. 103, no. 7, pp. 764-767, 2004.

[2] J. Yang, Z. Yang, G. D. Zhang, Y. W. Tang, and H. P. Chen, "Experimental research on the mixed sand ratio and initial dry density of weathered sand improved expansive soil free load swelling rate," Engineering Science, vol. 12, no. 3, pp. 77-83, 2014.

[3] S. C. Qi and S. K. Vanapall, "Hydro-mechanical coupling effect on surficial layer stability of unsaturated expansive soil slopes," Computers \& Geotechnics, vol. 70, pp. 68-82, 2015.

[4] C. W. W. Ng, L. T. Zhan, C. G. Bao, D. G. Fredlund, and B. W. Gong, "Performance of an unsaturated expansive soil slope subjected to artificial rainfall infiltration," Geotechnique, vol. 53, no. 2, pp. 143-157, 2003.

[5] A. Gens and E. E. Alonso, "A framework for the behaviour of unsaturated expansive clays," Canadian Geotechnical Journal, vol. 29, no. 6, pp. 1013-1032, 1992.

[6] E. E. Alonso, A. Gens, and A. Josa, "A constitutive model for partially saturated soils," Géotechnique, vol. 40, no. 3, pp. 405-430, 1990.

[7] P. C. Knodel, A. E. Dif, and W. F. Blumel, "Expansive soils under cyclic drying and wetting," Geotechnical Test Journal, vol. 14, no. 1, pp. 96-102, 1991.

[8] A. A. Basma, A. S. Al-Hamoud, A. I. H. Malkawi, and M. A. AlBashabsheh, "Swelling-shrinkage behavior of natural expansive clays," Applied Clay Science, vol. 11, no. 1-4, pp. 211-227, 1996.

[9] A. S. Al-Homoud, A. A. Basma, A. I. H. Malkawi, and M. A. A. Bashabsheh, "Cyclic swelling behavior of clays," Journal of Geotechnical Engineering, vol. 121, no. 7, pp. 562565, 1995.

[10] Y. Dong and B. T. Wang, "Test study on mechanical properties of the lime stabilized expansive soil under wet and dry cycle," Applied Mechanics and Materials, vol. 174-177, pp. 166-170, 2012.

[11] B. D. Kay and A. R. Dexter, "The influence of dispersible clay and wetting-drying cycles on the tensile strength of a redbrown earth," Australian Journal of Soil Research, vol. 30, no. 3, pp. 297-310, 1992.

[12] H. P. Yang and D. Xiao, "The influence of alternate dry-wet effect on the strength characteristic of expansive soils," Journal of Hunan Light Industry College, vol. 4, no. 4, pp. 1-5, 2005.

[13] M. A. Malusis, S. Yeom, and J. C. Evabs, "Hydraulic conductivity of model soil-bentonite backfills subjected to wetdry cycling," Canadian Geotechnical Journal, vol. 48, no. 8, pp. 1198-1211, 2011.

[14] Z. J. Zhang, M. J. Tao, and M. Morvant, "Cohesive slope surface failure and evaluation," Journal of Geotechnical and Geoenvironmetal Engineering, vol. 131, no. 7, pp. 898-906, 2005.

[15] B. X. Shi, S. S. Chen, H. Q. Han, and C. F. Zheng, "Expansive soil crack depth under cumulative damage," Scientific World Journal, vol. 2014, Article ID 498437, 9 pages, 2014.

[16] G. Wang and X. Wei, "Modeling swelling-shrinkage behavior of compacted expansive soils during wetting-drying cycles," Canadian Geotechnical Journal, vol. 1, no. 6, pp. 783-794, 2015.

[17] S. M. Rao, B. V. V. Reddy, and M. Muttharam, "Effect of cyclic wetting and drying on the index properties of a lime-stabilised expansive soil," Ground Improvement, vol. 5, no. 3, pp. 107110, 2001.

[18] C. B. Yang, F. S. Zha, and K. R. Cui, "Effect of cyclic wetting and drying on the engineering properties of stabilized expansive soils," Industrial Construction, vol. 42, no. 1, pp. 98-102, 2012, in Chinese.

[19] J. K. Mitchell, Fundamentals of Soil Behavior, Wiley \& Sons, New York, NY, USA, 1993.

[20] S. X. Chen, Y. Song, L. W. Kong, A. G. Guo, and G. S. Liu, "Study on approach to identification and classification of expansive soils," Rock and Soil Mechanics, vol. 26, no. 12, pp. 1895-1900, 2005, in Chinese.

[21] H. Duan, S. X. Chen, F. Yu, and X. C. Xu, "Applicability of recommended classification in specification method for expansive soil in the middle area of Anhui province," Chinese Journal of Rock Mechanics and Engineering, vol. 25, no. 10, pp. 2121-2127, 2006, in Chinese. 
[22] Urban-Rural Development of the People's Republic of China, Technical Code for Buildings in Expansive Soil Regions (GB50112-2013), China Architecture \& Building Press, Beijing, China, 2012.

[23] F. S. Zha, J. J. Liu, L. Xu, and K. R. Cui, "Cyclic wetting and drying tests on heavy metal contaminated soils solidified/ stabilized by cement," Journal of Geotechnical Engineering, vol. 35, no. 7, pp. 1246-1252, 2013, in Chinese.

[24] ASTM, "Standard test method for wetting and drying test of solid wastes," in Annual Book of ASTM Standards D4843-88, American Society of Testing and Materials (ASTM), West Conshohocken, PA, USA, 2016.

[25] ASTM, "Standard test method for unconfined compressive strength of cohesive soil," Annual Book of ASTM Standards D2166-06, American Society of Testing and Materials (ASTM), West Conshohocken, PA, USA, 2006.

[26] ASTM, "Standard test methods for liquid limit, plastic limit, and plasticity index of soil," Annual Book of ASTM Standards D4318-17, American Society of Testing and Materials (ASTM), West Conshohocken, PA, USA, 2010. 


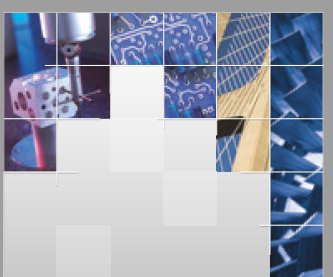

\section{Enfincering}
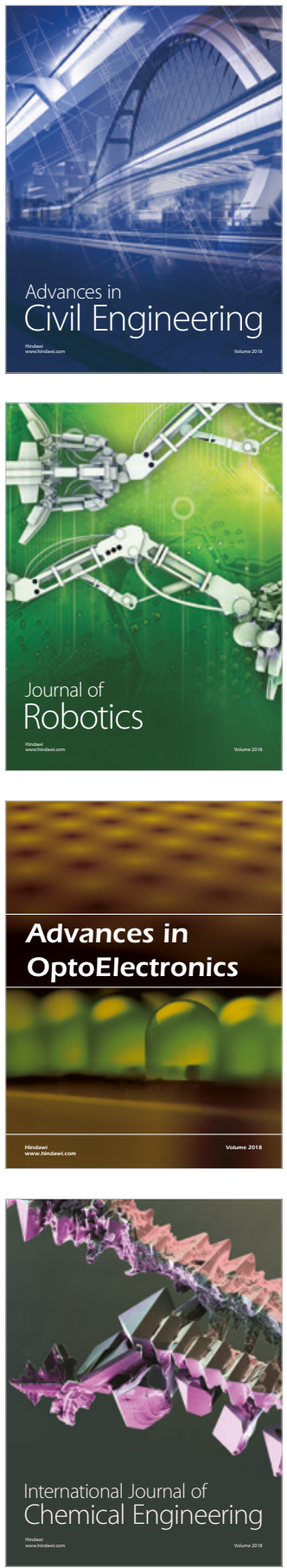

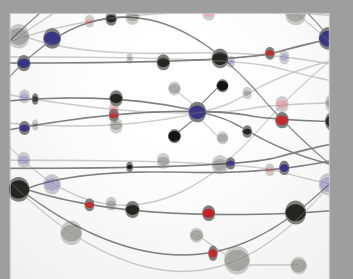

\section{Rotating \\ Machinery}

The Scientific World Journal

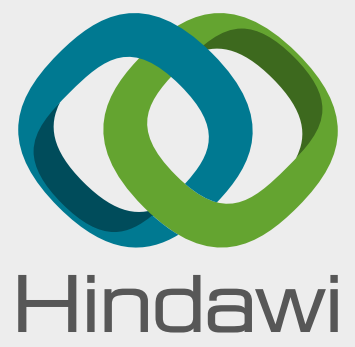

Submit your manuscripts at

www.hindawi.com
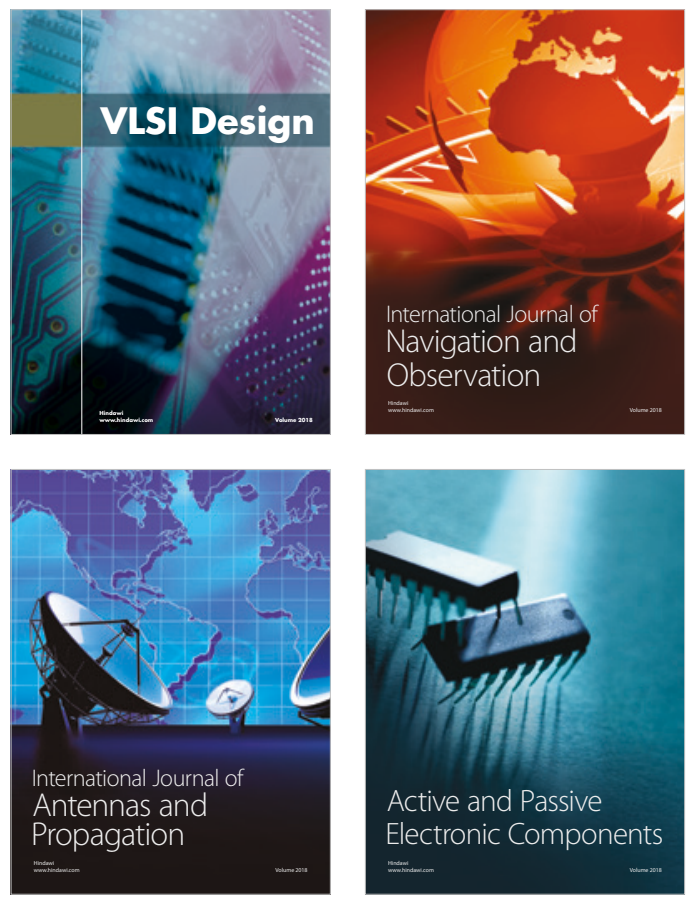
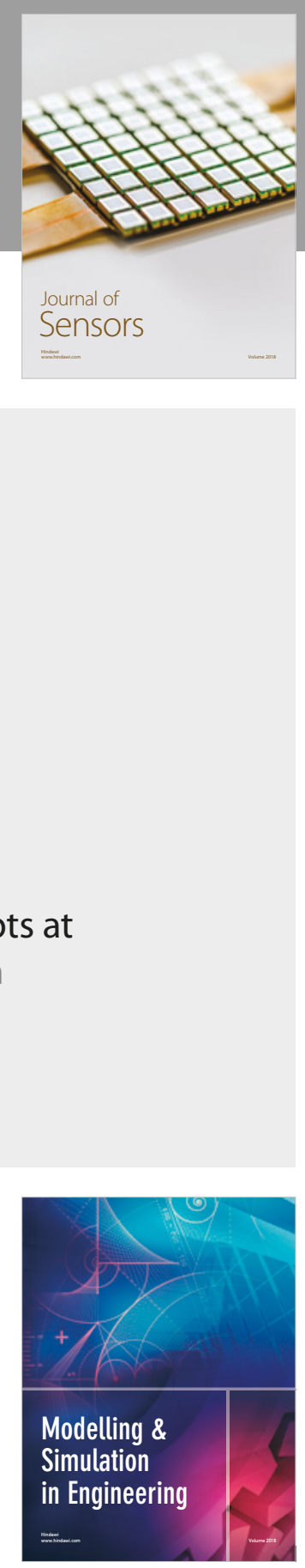

\section{Advances \\ Multimedia}
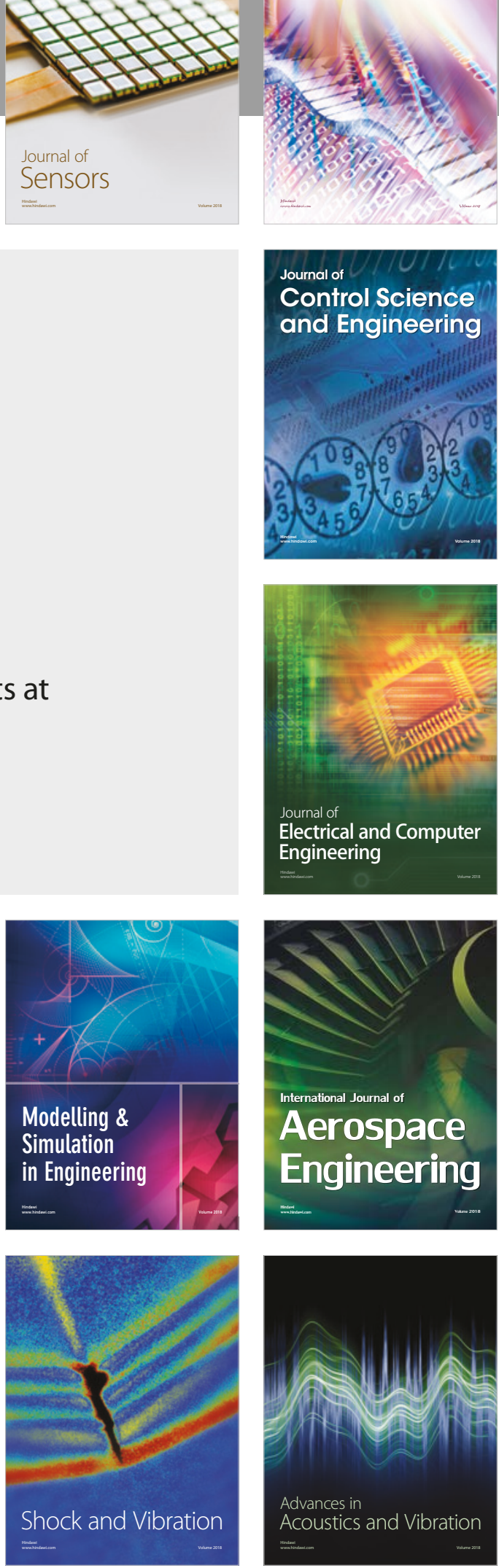